\title{
FOLLOW-UP OF PATIENTS WITH SEVERE PULMONARY HYPERTENSION AFTER MITRAL VALVE REPLACEMENT
}

\author{
By \\ Khaled Mohamed Mohamed Ali, Mohamed Shaffik Hassan Abdallah, \\ Medhat Ahmed Refaie Mohamed and Haytham Mohamed Abd El-Moaty \\ Hussein \\ Cardiothoracic Surgery Department, Faculty of Medicine, Al-Azhar University \\ *Corresponding Author: Khaled Mohamed Mohamed Ali, \\ E-mail: sur.khalidsoliman@gmail.com
}

\begin{abstract}
Background: Pulmonary hypertension ( $\mathrm{PH}$ ) occurs with an overall prevalence estimated at 15 per one million individuals. $\mathrm{PH}$ is only defined in the resting state and is present when the catheter derived mean pulmonary artery pressure (mPAP) exceeds $25 \mathrm{mmHg}$.

Objective: To assess the clinical, echocardiographic, and hemodynamic changes occurring to patients with severe pulmonary hypertension after mitral valve replacement in early and mid-term period.

Patients and methods: This study included 40 patients, who underwent mitral valve replacement for mitral valve disease with severe $\mathrm{PH}>50 \mathrm{mmHg}$ ) were studied prospectively for immediate and midterm (after 2 years) postoperative hemodynamics and outcomes. This study was conducted in Shebeen El-Koom Teaching Hospital during the period August 2016 to December 2019.

Results: The early and mid-term results of mitral valve replacement in patients with pulmonary hypertension were good with functional improvement and reduction of pulmonary hypertension. By the end of the study, some complications, which were successfully managed, were reported and survival at two years was $92.5 \%$.

Conclusion: Mitral valve replacement (MVR) was safe and effective operation even in patients with severe pulmonary hypertension (PH) with acceptable operative mortality, and a significant improvement in echocardiographic parameters, pulmonary pressure, and NYHA classification.
\end{abstract}

Keywords: Mitral Valve Replacement, Pulmonary Hypertension, Mean Pulmonary Artery Pressure.

\section{INTRODUCTION}

Pulmonary hypertension is a common finding in the preoperative evaluation in patients who have mitral valve disease (Thunberg et al., 2013), often resulting from elevated left atrial pressures that lead to pulmonary vascular remodeling. Longstanding $\mathrm{PH}$ increases the afterload on the right ventricle, leading to hypertrophy and eventually, cor pulmonale (McLaughlin et al., 2010).

Pulmonary hypertension $(\mathrm{PH})$ is defined as a mean pulmonary artery pressure $(\mathrm{mPAP})$ of $\geq 25 \mathrm{mmHg}$ or $>30$ $\mathrm{mmHg}$ during exercise (equivalent to a pulmonary artery systolic pressure, PASP, of $>43 \mathrm{mmHg}$ (Nishimura et al., 2014).

Pulmonary Hypertension Can be further stratified into moderate $(<49 \mathrm{~mm}$ 
$\mathrm{Hg}$ ), severe (50-79 $\mathrm{mm} \mathrm{Hg}$ ), and extreme $(\geq 80 \mathrm{~mm} \mathrm{Hg}$ ). Preoperatively, PASP is either measured directly via right-heart catheterization (RHC), or estimated via Doppler echocardiography, using the simplified Bernoulli equation (Enter et al., 2016).

Group $2 \mathrm{PH}$ in patients with left-sided cardiac disease $\mathrm{PH}$ has been reported in greater than $60 \%$ of patients with left ventricular systolic dysfunction, greater than $80 \%$ of patients with left ventricular diastolic dysfunction, and in $78 \%$ of patients prior to mitral valve surgery (Magne et al., 2015). Pulmonary hypertension $(\mathrm{PH})$ historically has been considered a mortality risk factor in cardiac surgical patients, and is found in $15 \%$ to $60 \%$ of patients who have valvular heart disease. $\mathrm{PH}$ is associated with a higher risk of cardiovascular events with medical management, during valve surgery, and even after successful surgical intervention (Nishimura et al., 2014).

Symptoms like orthopnea and paroxysmal nocturnal dyspnea are more specific for left-sided $\mathrm{PH}$, but the most common symptom is exertional dyspnea. Chest radiography will often reveal cardiomegaly, pulmonary vascular congestion, excessive extravascular lung water, pleural effusion, or pulmonary edema. Electrocardiographic clues favoring group $2 \mathrm{PH}$ include LV hypertrophy, left atrial enlargement, or atrial fibrillation .High-resolution chest computed tomography will often reveal a mosaic perfusion pattern and ground-glass opacities consistent with chronic interstitial lung edema. Pulmonary function tests may document a restrictive pulmonary pattern, and gas diffusion is generally reduced according to PVR and PAP increase. Plasma natriuretic peptide levels may be increased in any type of $\mathrm{PH}$, but tend to be the highest in group 2, particularly when LVEF is depressed (Song et al., 2015).

Transthoracic echocardiography is recommended as a diagnostic and screening test in the evaluation of suspected $\mathrm{PAH}$, and this will provide essential information regarding concomitant left-sided valvular or ventricular dysfunction. In some instances, as disagreement between LV end-diastolic pressure (LVEDP) and PCWP in some patients, invasive hemodynamic evaluation with right heart catheterization (swan-ganz catheter) is required to confirm the diagnosis (Jorge et al., 2016).

This right-heart failure is associated with tricuspid annulus, right ventricular dilation, and tricuspid regurgitation, further exacerbating right ventricular dysfunction (Magne et al., 2015). Current guidelines suggest that the most effective therapy for severe degenerative mitral regurgitation is surgical intervention (Nishimura et al., 2014).

Up to $50 \%$ of patients undergoing MVS have tricuspid valve regurgitation, which has been shown to negatively affect survival independently (De Meester et al., 2015). Current guidelines provide a Class I indication for repair of severe tricuspid regurgitation for patients undergoing leftsided valve surgery (Nishimura et al., 2014), consistent with long-term outcomes demonstrating a survival advantage of tricuspid valve repair concomitant with MVS (Navia et al., 2012). 
The present work aimed to assess the clinical, echocardiographic, and hemodynamic changes occurring to patients with severe pulmonary hypertension after mitral valve replacement in early and mid-term period.

\section{PATIENTS AND METHODS}

This study included 40 patients, who underwent mitral valve replacement for mitral valve disease with severe $\mathrm{PH}>50$ $\mathrm{mmHg}$ ) were studied prospectively for immediate and midterm (after 2 years) postoperative hemodynamics and outcomes. This study was conducted in Shebeen El-Koom Teaching Hospital during the period August 2016 to December 2019. We have measured PAP pre-operatively using transthoracic echocardiography then using direct measurement by arterial cannula intraoperatively then measured by transthoracic echocardiography in postoperative follow-up.

\section{All patients were subjected to:}

\section{Preoperative evaluation:}

Through full history taking and full clinical examination were done. Preoperative laboratory investigation were done including Complete blood count (CBC), erythrocyte sedimentation rate (ESR), C-reactive protein (CRP), random and fasting blood sugar (RBS and FBS), liver and kidney functions, $\mathrm{ABO}$ compatibility, coagulation profile, virology screening and lipid profile. Radiological assessment included chest Xray erect (postero-anterior and lateral view) and CT chest for every patient older than 60 years. Cardiac investigations included ECG, Echocardiography and
Coronary angiography for patients older than 40 years were done.

After approval of all preoperative results, patients were scheduled electively for mitral valve replacement surgery (MVR).Investigations were performed at baseline, early after surgery, One week, Three months, Six months and two years later.

\section{Operative technique:}

All patients underwent conventional mitral valve replacement through median sternotomy. The patient was placed supine on the operating table under general anesthesia. The chest, abdomen, perineum and lower extremities were prepped and draped in sterile fashion. An arterial line was placed through left radial artery.

\section{Post-operative:}

Patients were transferred intubated to the ICU. The immediate postoperative care focused on control of blood pressure and maintenance of adequate filling pressures with help of inotropic drugs.

With stable hemodynamics, patients were transferred to the ward, echocardiography one week post-operative was done. Patients were followed for few days until target INR is achieved and wound is clean, and then patient was discharged home.

Patient came to follow up at outpatient clinic after 1 week, 1 month and 3 months, with routine examination of hemodynamics and wound state every visit. Chest $\mathrm{x}$-ray and Echocardiography were requested at 1-week, 3-months follow- up, 6-months follow-up and 2 years follow-up visits. 


\section{Statistical analysis:}

Data were collected, coded, revised and entered to the Statistical Package for Social Science (IBM SPSS) version 20. The data were presented as number and percentages for the qualitative data, mean, standard deviations and ranges for the quantitative data with parametric distribution and median with inter quartile range (IQR) for the quantitative data with non-parametric distribution. Chi-square test was used in the comparison with qualitative data and Fisher exact test was used instead of the Chi-square test when the expected count in any cell found less than 5. Paired t-test was used in the comparison in quantitative data for the before and after. The confidence interval was set to $95 \%$ and the margin of error accepted was set to $5 \%$. So, the p-value was considered significant as the when $\mathrm{p}<0.05$.

\section{RESULTS}

For sex distribution, there were (26 females and 14 male). The males were (35\%) while females were $(65 \%)$. These patients were between 20 and 68 years of age. The mean age of patients included was $(36.73 \pm 9.62)$ years. Regarding body surface area (BSA), the mean was (1.72 \pm $0.08) \mathrm{m}^{2}$ with range from 1.65 to 2 (Table 1).

Table (1): Demographic data in the total group

\begin{tabular}{|c|c|c|c|}
\hline \multirow{2}{*}{ Parameters } & Total group (No.=40) & No & $\%$ \\
\hline \multirow{2}{*}{ Gender } & Male & 14 & $35.0 \%$ \\
\cline { 2 - 4 } & Female & 26 & $65.0 \%$ \\
\hline \multirow{2}{*}{ Age of patients(years) } & Mean \pm SD & $36.73 \pm 9.62$ \\
\cline { 2 - 3 } & Range(years) & $20-68$ \\
\hline \multirow{2}{*}{ BSA $/ \mathbf{m}^{\mathbf{2}}$} & Mean \pm SD & $1.72 \pm 0.08$ \\
\cline { 2 - 3 } & Range & \multicolumn{2}{|c}{$1.65-2$} \\
\hline
\end{tabular}

LVEDD was $(4.79 \pm 0.42) \mathrm{cm}$ and LVESD, mean \pm SD was $(3.28 \pm 0.26)$ $\mathrm{cm}$. All patients had considerable Left Atrial (LA) enlargement, the size ranging from 5 to $8 \mathrm{~cm} ; 8$ had giant LA $(>6.5$ $\mathrm{cm})$.The mean \pm SD of (LA) was $(6.40 \pm$ $0.69) \mathrm{cm}$ and $\mathrm{EF}$ was $(58.68 \pm 3.79) \%$. The Right Ventricle (RV) dimension was 2.4 to $4.9 \mathrm{~cm}, \mathrm{RV}$ dilatation $(>3.0 \mathrm{~cm})$ was seen in 37 patients $(92.5 \%)$, which was mild $(3.1-3.5 \mathrm{~cm})$ in 11 patients, moderate $(3.6-4 \mathrm{~cm})$ in 23 patients, and significant $(>4)$ in 3 patients. The mean \pm
$\mathrm{SD}$ of (RV) was $(3.32 \pm 0.59) \mathrm{cm}$. The Right Atrium (RA) varied from 2.5 to 6 $\mathrm{cm}$. The mean \pm SD of (RA) was $(4.39 \pm$ $0.87) \mathrm{cm}$. Dominant MS was defined as a mitral valve orifice area $<1.0 \mathrm{~cm} 2$, dominant MR was defined as a ratio of jet area to left atrial area $>40 \%$, and a mixed lesion met the criteria for both MS and MR. In total group, the dominant valvular lesion was mitral stenosis (MS) in 21 $(52.5 \%)$ patients, mitral regurgitation (MR) 6 patients (15\%), and mixed lesions in $13(32.5 \%)$ patients (Table 2).

Table (2): Distribution according Baseline preoperative Echocardiographic data 
FOLLOW-UP OF PATIENTS WITH SEVERE PULMONARY...

\begin{tabular}{|c|c|c|c|c|}
\hline \multicolumn{2}{|c|}{$\begin{array}{ll}\text { Parameters } & \text { Total Group }(\text { No. }=40) \\
\end{array}$} & Min. & Max. & Mean \pm SD \\
\hline \multicolumn{2}{|c|}{ LVEDD $(\mathrm{cm})$} & 3.9 & 5.7 & $4.79 \pm 0.42$ \\
\hline \multicolumn{2}{|c|}{ LVESD $(\mathrm{cm})$} & 2.8 & 3.9 & $3.28 \pm 0.26$ \\
\hline \multicolumn{2}{|c|}{$\mathbf{L A}(\mathrm{cm})$} & 5 & 8 & $6.40 \pm 0.69$ \\
\hline \multicolumn{2}{|c|}{$\mathrm{EF}(\%)$} & 48 & 65 & $58.68 \pm 3.79$ \\
\hline \multicolumn{2}{|c|}{ R Ventricle $(\mathrm{cm})$} & 2.4 & 4.9 & $3.32 \pm 0.59$ \\
\hline \multirow{2}{*}{\multicolumn{2}{|c|}{ R Atrium $(\mathrm{cm})$}} & 2.5 & 6 & $4.39 \pm 0.87$ \\
\hline & & \multicolumn{2}{|c|}{ No } & $\%$ \\
\hline \multirow{3}{*}{$\begin{array}{l}\text { Dominant } \\
\text { Mitral Lesion }\end{array}$} & Mitral Stenosis & \multicolumn{2}{|c|}{21} & $52.5 \%$ \\
\hline & Mitral regurge & \multicolumn{2}{|c|}{6} & $15.0 \%$ \\
\hline & Mixed Lesion & \multicolumn{2}{|c|}{13} & $32.5 \%$ \\
\hline \multirow{5}{*}{$\begin{array}{c}\text { Tricuspid Regurge } \\
\text { Severity }\end{array}$} & Nill & \multicolumn{2}{|c|}{6} & $15 \%$ \\
\hline & Trivial & \multicolumn{2}{|c|}{4} & $10 \%$ \\
\hline & Mild & \multicolumn{2}{|c|}{11} & $27.5 \%$ \\
\hline & Moderate & \multicolumn{2}{|c|}{15} & $37.5 \%$ \\
\hline & Severe & \multicolumn{2}{|c|}{4} & $10 \%$ \\
\hline
\end{tabular}

SPAP mean \pm SD was $(54.65 \pm 7.55)$ $\mathrm{mmHg}$ with range from 42 to 72 . LVEDD mean \pm SD was $(4.65 \pm 0.40)$ with range from 3.8 to 5.4, LVESD mean \pm SD was $(3.51 \pm 0.30) \mathrm{cm}$ with range from 3 to 4.1 and Left atrial size (LA) mean \pm SD was $(5.29 \pm 0.64) \mathrm{cm}$ with range from 4 to 6.7 . $\mathrm{EF}$ mean $\pm \mathrm{SD}$ was $(59.38 \pm 3.15)$ with range from 52 to 65 and the mean \pm SD of $(\mathrm{RV})$ was $(3.21 \pm 0.51) \mathrm{cm}$ with range from 2.4 to 4.5 and the mean \pm SD of (RA) was
$(4.32 \pm 0.80) \mathrm{cm}$ with range from 2.5 to 5.8. Tricuspid regurgitation (TR) varied from normal in 6 patients, trivial in 7 patients, mild in 13 patients, moderate in 12 patients and 2 cases with severe degree.

The mean of SPAP decreased significantly by $22.3 \%$ from a mean preoperative level of $70.35 \pm 6.78$ to $54.65 \pm 7.55 \mathrm{mmHg}$ within one week following MVR ( $<<0.001)$ (Table 3).

Table (3): Comparison between baseline and after one week according echocardiographic data in Overall cases

\begin{tabular}{|c|c|c|c|c|c|}
\hline \multirow{2}{*}{ Parameters } & Baseline & One week & \multirow{2}{*}{$\begin{array}{c}\text { Mean } \\
\text { difference }\end{array}$} & \multirow{2}{*}{$\begin{array}{l}\text { Percentage } \\
\text { of Change }\end{array}$} & \multirow{2}{*}{$\begin{array}{c}P \\
\text { value }\end{array}$} \\
\hline & Mean \pm SD & Mean \pm SD & & & \\
\hline SPAP & $70.35 \pm 6.78$ & $54.65 \pm 7.55$ & -15.7 & $-22.3 \%$ & $<0.001$ \\
\hline LVEDD & $4.79 \pm 0.42$ & $4.64 \pm 0.40$ & 0.15 & $-3.1 \%$ & 0.105 \\
\hline LVESD & $3.28 \pm 0.26$ & $3.51 \pm 0.30$ & -0.23 & $7.0 \%$ & $<0.001$ \\
\hline LA & $6.40 \pm 0.69$ & $5.29 \pm 0.64$ & 1.11 & $-17.3 \%$ & $<0.001$ \\
\hline $\mathbf{E F}$ & $58.68 \pm 3.79$ & $59.38 \pm 3.15$ & -0.70 & $1.2 \%$ & 0.372 \\
\hline R. Ventricle & $3.32 \pm 0.59$ & $3.21 \pm 0.51$ & 0.10 & $-3.3 \%$ & 0.408 \\
\hline R. Atrium & $4.39 \pm 0.87$ & $4.32 \pm 0.80$ & 0.07 & $-1.6 \%$ & 0.709 \\
\hline
\end{tabular}

SPAP mean \pm SD was $(39.38 \pm 5.82)$ $\mathrm{mmHg}$ with range from 31 to 53 and
LVEDD mean \pm SD was $(4.27 \pm 0.39)$ with range from 3.6 to 5 . LVESD mean \pm 
SD was $(3.56 \pm 0.64) \mathrm{cm}$ with range from 3 to 4 and Left atrial size (LA) mean \pm SD was $(4.70 \pm 0.39)$ with range from 4.2 to 5.8. EF mean \pm SD was $(60.85 \pm 2.62)$ with range from 53 to 65 . The mean \pm SD of $(\mathrm{RV})$ was $(3.08 \pm 0.37)$ with range from 2.4 to 3.9 and the mean \pm SD of (RA) was $(3.92 \pm 0.57) \mathrm{cm}$ with range from 2.5 to 4.8. Tricuspid regurgitation (TR) varied from normal in 7 patients, trivial in 12 patients, mild in 11 patients, moderate in 9 patients without any cases with severe degree.

The mean of SPAP decreased significantly by $44 \%$ from a mean preoperative level of $(70.35 \pm 6.78)$ to $(39.38 \pm 5.82) \mathrm{mmHg}$ within Three months later $(\mathrm{p}<0.001)$ (Table 4).

Table (4): Comparison between baseline and after 3 months according echocardiographic data

\begin{tabular}{|c|c|c|c|c|c|}
\hline \multirow{2}{*}{ Parameters } & Baseline & 3 months & \multirow{2}{*}{$\begin{array}{c}\text { Mean } \\
\text { difference }\end{array}$} & \multirow{2}{*}{$\begin{array}{l}\text { Percentage } \\
\text { of Change }\end{array}$} & \multirow{2}{*}{$\begin{array}{c}\mathbf{P} \\
\text { value }\end{array}$} \\
\hline & Mean \pm SD & Mean \pm SD & & & \\
\hline SPAP & $70.35 \pm 6.78$ & $39.38 \pm 5.82$ & -30.97 & $-44 \%$ & $<0.001$ \\
\hline LVEDD & $4.79 \pm 0.42$ & $4.27 \pm 0.39$ & 0.51 & $-10.9 \%$ & $<0.001$ \\
\hline LVESD & $3.28 \pm 0.26$ & $3.56 \pm 0.64$ & -0.28 & $8.5 \%$ & $<0.001$ \\
\hline LA & $6.40 \pm 0.69$ & $4.70 \pm 0.39$ & 1.70 & $-26.6 \%$ & $<0.001$ \\
\hline EF & $58.68 \pm 3.79$ & $60.85 \pm 2.62$ & -2.17 & $3.7 \%$ & 0.004 \\
\hline R. Ventricle & $3.32 \pm 0.59$ & $3.08 \pm 0.37$ & 0.23 & $-7.2 \%$ & 0.041 \\
\hline R. Atrium & $4.39 \pm 0.87$ & $3.92 \pm 0.57$ & 0.47 & $-10.7 \%$ & 0.006 \\
\hline
\end{tabular}

SPAP mean \pm SD was $(31.21 \pm 6.97)$ $\mathrm{mmHg}$ with range from 22 to 47 and LVEDD mean \pm SD was $(4.19 \pm 0.77) \mathrm{cm}$ with range from 4 to 5 . LVESD mean \pm $\mathrm{SD}$ was $(3.61 \pm 0.37) \mathrm{cm}$ with range from 3 to 4.1 and Left atrial size (LA) mean \pm $\mathrm{SD}$ was $(4.63 \pm 0.37) \mathrm{cm}$ with range from 4.2 to 5.5 . EF mean \pm SD was $(61.21 \pm$ 2.28 ) with range from 55 to 65 . The mean $\pm \mathrm{SD}$ of $(\mathrm{RV})$ was $(2.93 \pm 0.37) \mathrm{cm}$ with range from 2.4 to 3.8 and the mean $\pm \mathrm{SD}$ of (RA) was $(3.47 \pm 0.34) \mathrm{cm}$ with range from 2.8 to 4.2 . Tricuspid regurgitation
(TR) varied from normal in 10 patients, trivial in 14 patients, mild in 7 patients, moderate in 8 patients and without any cases with severe degree.

The mean of SPAP decreased significantly by $55.6 \%$ from a mean preoperative level of $(70.35 \pm 6.78)$ to (31.21 \pm 6.97$) \mathrm{mmHg}$ within Six months later $(\mathrm{p}<0.001)$. NYHA class Six Months Later: According to NYHA classification: $27(69.5 \%)$ patients were NYHA I, 11 (28\%) patients were NYHA II and 1 (2.5\%) patients were NYHA III (Table 5).

Table (5): Comparison between baseline and after 6 months according echocardiographic data in total group 


\begin{tabular}{|c|c|c|c|c|c|}
\hline \multirow{2}{*}{ Parameters } & Baseline & $6 \mathrm{~m}$ & \multirow{2}{*}{$\begin{array}{c}\text { Mean } \\
\text { difference }\end{array}$} & \multirow{2}{*}{$\begin{array}{l}\text { Percentage } \\
\text { of Change }\end{array}$} & \multirow{2}{*}{$\begin{array}{c}\mathbf{P} \\
\text { value }\end{array}$} \\
\hline & Mean \pm SD & Mean \pm SD & & & \\
\hline SPAP & $70.35 \pm 6.78$ & $31.21 \pm 6.97$ & -39.14 & $-55.6 \%$ & $<0.001$ \\
\hline LVEDD & $4.79 \pm 0.42$ & $4.19 \pm 0.77$ & 0.60 & $-12.5 \%$ & $<0.001$ \\
\hline LVESD & $3.28 \pm 0.26$ & $3.61 \pm 0.37$ & -0.33 & $10 \%$ & $<0.001$ \\
\hline LA & $6.40 \pm 0.69$ & $4.63 \pm 0.37$ & 1.76 & $-27.7 \%$ & $<0.001$ \\
\hline EF & $58.68 \pm 3.79$ & $61.21 \pm 2.28$ & -2.53 & $4.3 \%$ & $<0.001$ \\
\hline R. Ventricle & $3.32 \pm 0.59$ & $2.93 \pm 0.37$ & 0.38 & $-11.7 \%$ & $<0.001$ \\
\hline R. Atrium & $4.39 \pm 0.87$ & $3.47 \pm 0.34$ & 0.92 & $-21.0 \%$ & $<0.001$ \\
\hline
\end{tabular}

SPAP mean \pm SD was $(28.03 \pm 5.34)$ $\mathrm{mmHg}$ with range from 20 to 42 and LVEDD mean \pm SD was $(4.14 \pm 0.36) \mathrm{cm}$ with range from 4 to 5 . LVESD mean \pm $\mathrm{SD}$ was $(3.62 \pm 0.58) \mathrm{cm}$ with range from 3.1 to 4.1 and Left atrial size (LA) mean \pm $\mathrm{SD}$ was $(4.53 \pm 0.24) \mathrm{cm}$ with range from 4 to 5 . EF mean \pm SD was $(62.38 \pm 2.06)$ with range from 59 to 65 . The mean $\pm \mathrm{SD}$ of $(\mathrm{RV})$ was $(2.81 \pm 0.25) \mathrm{cm}$ with range from 2.4 to 3.5 and the mean $\pm \mathrm{SD}$ of
(RA) was $(3.45 \pm 0.32) \mathrm{cm}$ with range from 2.8 to 4 . Tricuspid regurgitation (TR) varied from normal in 12 patients, trivial in 15 patients, mild in 3 patients, moderate in 7 patients and without any cases with severe degree.

The mean of SPAP decreased significantly by $60.15 \%$ from a mean preoperative level of $(70.35 \pm 6.78)$ to $(28.03 \pm 5.34) \mathrm{mmHg}$ within 2 years later $(\mathrm{p}<0.001)$ (Table 6).

Table (6): Comparison between baseline and after 2 years according echocardiographic data

\begin{tabular}{|c|c|c|c|c|c|}
\hline \multirow{2}{*}{ Puration } & Baseline & 2 years & \multirow{2}{*}{$\begin{array}{c}\text { Mean } \\
\text { difference }\end{array}$} & \multirow{2}{*}{$\begin{array}{l}\text { Percentage } \\
\text { of Change }\end{array}$} & \multirow{2}{*}{$\begin{array}{c}P \\
\text { value }\end{array}$} \\
\hline & Mean \pm SD & Mean \pm SD & & & \\
\hline SPAP & $70.35 \pm 6.78$ & $28.03 \pm 5.34$ & -42.32 & $-60.15 \%$ & $<0.001$ \\
\hline LVEDD & $4.79 \pm 0.42$ & $4.14 \pm 0.36$ & 0.65 & $-13.5 \%$ & $<0.001$ \\
\hline LVESD & $3.28 \pm 0.26$ & $3.62 \pm 0.58$ & -0.34 & $10.3 \%$ & $<0.001$ \\
\hline LA & $6.40 \pm 0.69$ & $4.53 \pm 0.24$ & 1.87 & $-29.2 \%$ & $<0.001$ \\
\hline EF & $58.68 \pm 3.79$ & $62.38 \pm 2.06$ & -3.70 & $6.3 \%$ & $<0.001$ \\
\hline R. Ventricle & $3.32 \pm 0.59$ & $2.81 \pm 0.25$ & 0.50 & $-15.4 \%$ & $<0.001$ \\
\hline R. Atrium & $4.39 \pm 0.87$ & $3.45 \pm 0.32$ & 0.94 & $-21.4 \%$ & $<0.001$ \\
\hline
\end{tabular}

NYHA class Two years later: According to NYHA classification: 30 (81\%) patients were NYHA I, 7 (19\%) patients were NYHA II.

Regarding mortality and morbidity; there were three cases of mortality; the first case was in the first month, the second case was in the eleventh-month post-operative and the third case died in the sixteenth-month post-operative due to hemodynamic instability, acute heart failure, low cardiac output syndrome, and sepsis. So regarding mortality; there were 3 cases $(7.5 \%)$. There were 4 cases developed pleural effusion of serous fluid. Three patients $(7.5 \%)$ was again admitted within the first six months in cardiology department with rapid AF. There were 8 patients (20\%) were Morbidity due to Anticoagulation (Figure 1). 
KHALED M. ALI et al.,

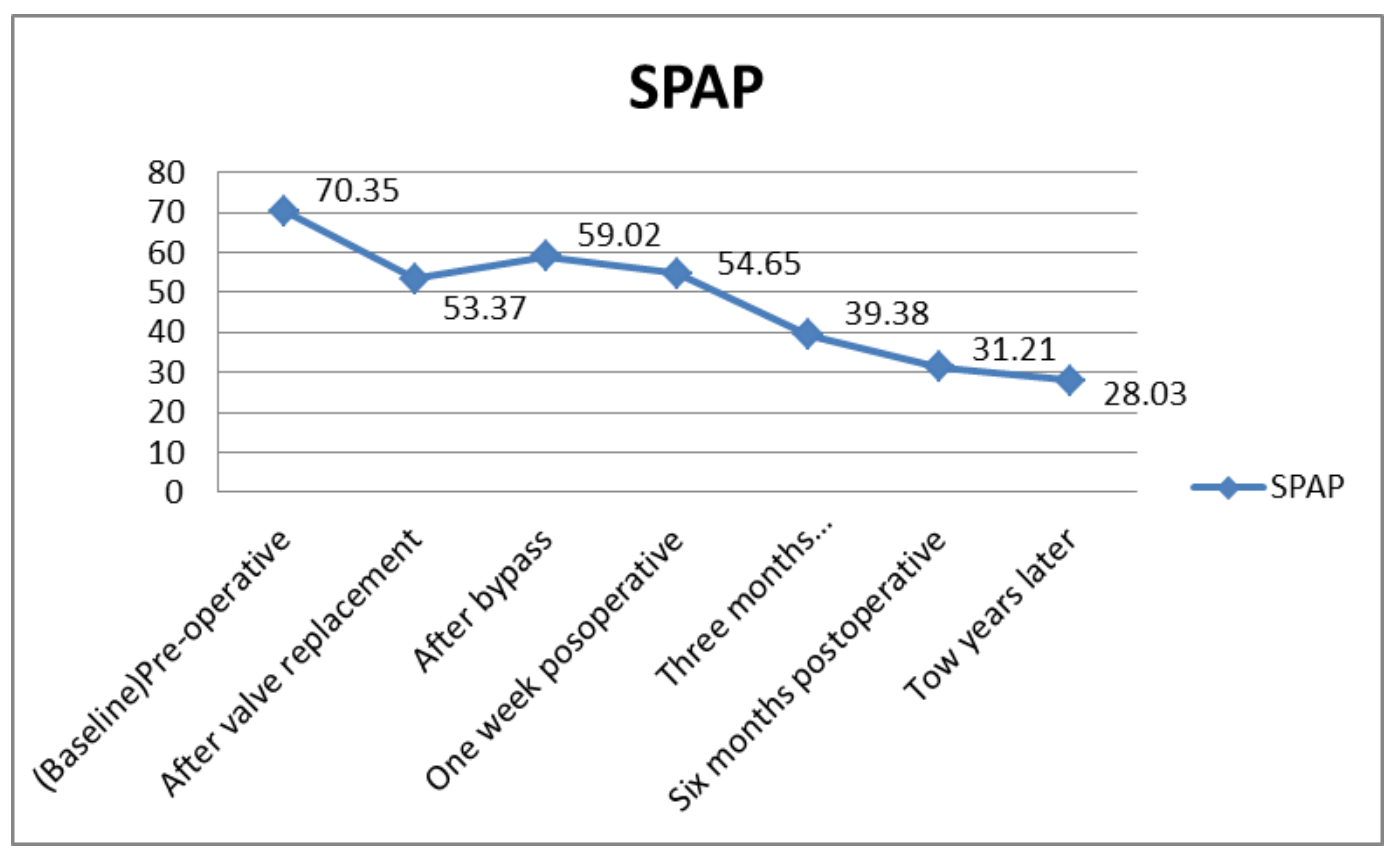

Figure (1): SPAP changes throughout the study

\section{DISCUSSION}

The present study revealed that the patients were predominantly females as they represented $65 \%$ of patients. The mean age of patients ranged from 20 to 68 years with a mean of $36.73 \pm 9.62$ years. The total body surface area of patients ranged from 1.65 to $2 \mathrm{~m} 2$ with a mean of $1.72 \pm 0.08 \mathrm{~m} 2$.

The higher incidence in women raises the suspicion of hormonal influences in the pathogenesis of pulmonary hypertension (PH); another possible explanation is sex difference in health seeking behavior for reporting health problems and seeking treatment (Dokhan et al., 2017), as well as the fact that male patients tend to die earlier from pulmonary hypertension (Shapiro et al., 2012). This higher incidence of pulmonary hypertension in females was reported in a number of previous studies as in the taskforce register in which the incidence in females was $70-80 \%$
(McGoon et al., 2013), as well as in the registery in which the female/male ratio was 2.3/1 in younger patients (median age 54 years), while in older patients (median age 75 years) this ratio was almost even, at 1.2/1 (Hoeper et al., 2013).

The present study revealed that the mean pre-operative SPAP in patients ranged from 60 to $85 \mathrm{mmHg}$ with a mean of $71.20 \pm 5.56 \mathrm{mmHg}$. Meanwhile, a different mean pre-operative SPAP of $62.1 \pm 35.2 \mathrm{mmHg}$ was reported by (Elwany et al., 2013), and this difference might be attributed to the different criteria of the included patients.

The present study revealed also that the dominant mitral lesion was mitral stenosis which was found in $52.5 \%$ of patients and that $37.5 \%$ of patients had tricuspid regurge of moderate severity. Pulmonary hypertension was similarly found to be associated with left atrial dilatation (Lee et al., 2016). Tricuspid regurge in this case is explained by the tricuspid annular 
dilatation which occurs as a result of right ventricular dilatation resulting from chronic pressure overload (Haddad et al., 2010). This is in addition to the effects of the altered right ventricular geometry and apical displacement of the tricuspid leaflets (Marechaux et al., 2011).

The current study revealed that the incidence of post-operative pulmonary hypertensive crisis in the included patients was $12.5 \%$. They experienced pulmonary hypertensive crisis (severe hypotension and cyanosis), sudden arrest or persistent hemodynamic instability and were managed by cardiac resuscitation with increasing the dose of inotropic support and pulmonary vasodilators, complete sedation and oxygen therapy. They stayed in the ICU for a mean duration of 3.79 \pm 1.29 days and the mean duration of their total hospital was $10.78 \pm 1.97$ days. Our results coincided with those obtained by Alassal et al. (2018) as they reported that duration of ICU stay in severe PH group of their study was $(3 \pm 0.5)$ days. But our results differ from those obtained by Kumar et al. (2013) as they reported that duration of ICU stay in severe $\mathrm{PH}$ group of their study (2.0 \pm 1.0$)$ days was less than the duration of ICU stay in our study. Regarding the total hospital stay, it was $10.78 \pm 1.97$ days, Our results were near to those obtained by Kumar et al. (2013) as they reported that total hospital stay in severe $\mathrm{PH}$ group of their study $(8 \pm 4)$ days.

As regards the pre-discharge NYHA classification of the included patients, the current study revealed that $42.5 \%$ of patients were NYHA I, $30 \%$ of them were NYHA II, $22.5 \%$ of them were NYHA III and 5\% were NYHA VI. Our results differed from those obtained by Bayat et al. (2013) as they reported that postoperative dyspnea according to NYHA classification in severe $\mathrm{PH}$ group of their study were $(36 \%)$ in class I, $(51 \%)$ in class II, and (13\%) in class III.

Regarding follow-up assessment of our patients after mitral valve replacement, we tracked the changes that happened to the pulmonary pressure and cardiac chambers at these times; One week, Three months, Six months and Two years post-operative which revealed that the overall assessment shows a statistically significant reduction in all parameters (SPAP, and chamber sizes and an improvement in NYHA and TR grade postoperatively). The parameters differed in their degree of regression as seen by percentage change. By comparison of the echocardiographic parameters at one week post-operative to the baseline pre-operative parameters of patients included in the present study revealed a highly statistically significant reduction in some parameters namely: SPAP, LVESD and LA. Meanwhile, the changes in the other parameters were not statistically significant.

This improvement can be explained by relieving the vasoactive component of $\mathrm{PH}$ followed by relief of the obstructive component by MVR and the reduction in LVEDD plays an important role in the regression of the pulmonary pressure which improves later, the right ventricular function (Bayat et al., 2013).

Regarding the total echocardiographic changes at three months post-operative and comparing them to the baseline preoperative parameters, revealed very highly statistically significant improvement in SPAP, LVEDD and LA with highly 
statistically significant improvement in LVESD, EF, RA and RV. This significant improvement is explained by relieving the vasoactive component of $\mathrm{PH}$ followed by relief of the obstructive component by MVR. The reduction in LVEDD plays an important role in the regression of the pulmonary pressure which improves later, the right ventricular function. This regression of the size of the LV was observed in a number of previous studies (Ghoreishi et al., 2011 and Song et al., 2015).

On the other hand, the total echocardiographic changes at six months post-operative and comparing them to the baseline pre-operative parameters, also revealed very highly statistically significant improvement $(\mathrm{p}<0.001)$ in most of the parameters (including SPAP, LA, EF, right atrium and right ventricle) as well as a highly statistically significant improvement in LVEDD and a statistically significant improvement in LVESD. And as before, it was in the same way by comparison of the echocardiographic parameters at two years post-operative to the baseline preoperative parameters revealed very highly statistically significant improvement $(\mathrm{p}<0.001)$ in all parameters.

Now clearly it can be said that the early changes (until six months) were significant in all, specifically for SPAP, LA, and RA. The late changes (until 2 years) were eminent for RV, RA, LA, and LV. As regards the NYHA classification of the included patients six months postoperative, the current study revealed that $69.5 \%$ of patients were NYHA class 1 , $28 \%$ of them were NYHA class 2 and $2.5 \%$ of them were NYHA class 3 . And as regards the NYHA classification of the included patients two years postoperative, the current study revealed that $81 \%$ of patients were NYHA class 1 and $19 \%$ of them were NYHA class 2.

As for SPAP changes throughout the study, the present study revealed these changes in systolic pulmonary artery pressure (SPAP) at early stages, then it increased slightly immediately afterbypass and giving protamine. Regarding their follow up echocardiography for postoperative SPAP; after one week, SPAP decreased at three months post-operatively six months post-operatively and later on SPAP.

The PASP showed an increase immediately after MVR, but it decreased significantly after that. Our results differ from Patel et al. (2014) these results also differ from those published by Kumar et al. (2013). Also Alassal et al. (2018) found that echocardiographic examination performed in the follow-up period at the end of first week, one, three and six months postoperatively revealed that in the early and late follow-up patients in both groups showed marked decrease in the pulmonary artery pressure PASP.

The significant reduction in SPAP detected in all stages of our study could be explained by the effect of inotropes, vasodilators and muscle relaxants used during induction in relieving the vasoactive component of pulmonary hypertension followed by relieve of obstructive component by MVR.

In early post-operative period after mitral valve replacement there was a slight increase in SPAP, Ram et al. (2019) indicated that pulmonary hypertension develops in the early postoperative period 
by way of at least three mechanisms. The first one is passive transmission due to increase in the left atrial pressure.

The second one is reactive pulmonary arteriolar vasoconstriction, and the last one is the development of morphologic alterations. The authors indicated that the first mechanism was rapidly reversible after MVR. They demonstrated that regression in other mechanisms occurred within a few months after MVR.

Numerous studies have examined hemodynamic changes in these patients at different intervals after mitral valve procedures. Most have demonstrated an immediate reduction in PAP and PVR, signifying a sudden drop in left atrial pressure and reversal of the severe spastic pulmonary vasoconstriction that accompanies left atrial hypertension in some patients (Mubeen et al., 2008).

By the end of the study, $7.5 \%$ of mortality were reported which occurred as a result of hemodynamic instability and acute heart failure complicated with low cardiac output syndrome and sepsis. Furthermore, $10 \%$ of patients developed pleural effusion, $7.5 \%$ of them developed $\mathrm{AF}$ and $20 \%$ of them developed complications related to anticoagulation therapy with thrombo-embolic complications. Lower mortality (3.1\%) was reported in surgically treated patients with severe pulmonary hypertension and mitral valve disease (Song et al., 2015).

This can be explained by the different criteria of included patients as well as the fact that their study was a retrospective study with assessment of the 3 year survival rate. On the contrary Ghoreishi et al. (2011) reported a hospital mortality of $12 \%$ in patients underwent mitral valve surgery with severe PHT. and they concluded that referral for MVS should be considered for patients who have PASP $40 \mathrm{~mm} \mathrm{Hg}$ or more lead to increased surgical risk.

\section{CONCLUSION}

There was a high prevalence of residual pulmonary hypertension after mid-term follow-up that was strongly correlated to older age of patients, smaller size of the prosthesis implanted and preoperative severe tricuspid regurge. These factors should be considered in order to improve the results of MVR in the follow-up.

\section{REFERENCES}

1. Alassal M, Rezk M, Fawzy E, Elnahas A and Mofreh B (2018): Mitral valve replacement in patients with extreme pulmonary hypertension: Tertiary center experience of 680 cases. J Cardiol \& Cardiovasc Ther., 9(2): 555759-64.

2. Bayat F, Aghdaii N, Farivar F, Bayat $A$ and Valeshabad AK (2013): Early hemodynamic changes after mitral valve replacement in patients with severe and mild pulmonary artery hypertension . Ann Thorac Cardiovasc Surg., 19:201-6.

3. De Meester P, De Cock D, Van De Bruaene A, Gabriels C and Buys $R$ (2015): Additional tricuspid annuloplasty in mitral valve surgery results in better clinical outcome. Heart, 101:720-6.

4. Dokhan AL, Abd El-Raouf ME, Ibrahim IM and Abdellatif MG (2017): Evaluation of early outcomes after mitral replacement in rheumatic 
heart patients with pulmonary hypertension. Menofia Medical Journal, 29:674-9.

5. Elwany SE, Mohamed AH and Abu El-Hussein AK (2013): Outcome after mitral valve replacement in patients with rheumatic mitral valve regurgitation and severe pulmonary hypertension. Egypt J Cardiothorac Anesth., 7(2):74-8.

6. Enter DH, Zaki A, Duncan BF, Kruse J, Andrei AC (2016): A contemporary analysis of pulmonary hypertension in patients undergoing mitral valve surgery: Is this a risk factor? J Thorac Cardiovasc Surg., 2151:1288-97.

7. Ghoreishi M, Evans CF, DeFilippi CR, Hobbs $G$ and Young CA (2011): Pulmonary hypertension adversely affects short- and long-term survival after mitral valve operation for mitral regurgitation: Implications for timing of surgery. $\mathrm{J}$ Thorac Cardiovasc Surg., 142:1439-52.

8. Haddad F, Couture P, Tousignant $C$ and Denault AY (2010): The right ventricle in cardiac surgery, a perioperative perspective: II. Pathophysiology, clinical importance and management. Anesth Analg., 108(2):422-33.

9. Hoeper MM, Huscher D, Ghofrani HA, Delcroix $M$ and Distler $O$ (2013): Elderly patients diagnosed with idiopathic pulmonary arterial hypertension: Results from the COMPERA registry. Int J Cardiol., 168(2):871-80.

10. Jorge E, Baptista R, Calisto J, Faria $H$ and Silva $C$ (2016):
Pulmonary vascular remodeling in mitral valve disease: An optical coherence tomography study. Int $\mathrm{J}$ Cardiol., 203:576-8.

11. Kumar N, Sevta P, Satyarthy S, Agarwal S and Betigeri VK (2013): Early results of mitral valve replacement in severe pulmonary artery hypertension - An institutional prospective study . World Journal of Cardiovascular Surgery, 3:63-9.

12. Lee S, Park SH, Choi JY, Na JO and Choi CU (2016): PS 11-10 Pulmonary hypertension severity is significantly related with left atrial diameter Journal of Hypertension, 34: 334-335.

13. Magne J, Pibarot $P$, Sengupta PP, Donal E and Rosenhek R (2015): Pulmonary hypertension in valvular disease: A comprehensive review on pathophysiology to therapy from the HAVEC Group. JACC Cardiovasc Imaging, 8(1):83-99.

14. Marechaux S, Neicu D, Braun S, Richardson $M$ and Delsart $P$ (2011): Functional mitral regurgitation: a link to pulmonary hypertension in heart failure with preserved ejection fraction. J Card Fail., 17(10):806-12.

15. McGoon MD, Benza RL, Escribano-Subias $P$, Jiang $X$ and Miller DP (2013): Pulmonary arterial hypertension: Epidemiology and registries. J Am Coll Cardiol., 62(25): 51-59.

16. McLaughlin VV, Archer SL, Badesch DB, Barst RJ and Farber HW (2010): ACCF/AHA 2010 expert consensus document on pulmonary 
hypertension: A report of the American College of Cardiology Foundation Task Force on Expert Consensus Documents and the American Heart Association, developed in collaboration with the American College of Chest Physicians; American Thoracic Society, Inc.; and the Pulmonary Hypertension Association, 53:1573619.

17. Navia JL, Brozzi NA, Klein AL, Ling LF and Kittayarak C (2012): Moderate tricuspid regurgitation with left-sided degenerative heart valve disease: To repair or not to repair. Ann Thorac Surg., 93:59-69.

18. Nishimura RA, Otto CM, Bonow RO, Carabello BA and Erwin JP (2014): AHA/ACC guideline for the management of patients with valvular heart disease: a report of the American College of Cardiology/American Heart Association Task Force on Practice Guidelines, 148:1-132.

19. Patel H, Desai M, Tuzcu EM, Griffin B and Kapadia $S$ (2014): Pulmonary hypertension in mitral regurgitation. JAHA, 3(4):748-53.

20. Ram E, Sternik L, Klempfner R, Eldar M, Goldenberg I, Peled Y, Raanani E and Kogan A. (2019):
Sildenafil for Pulmonary Hypertension in the Early Postoperative Period After Mitral Valve Surgery. J Cardiothorac Vasc Anesth., 33(6):1648-1656.

21. Shapiro S, Traiger GL, Turner M, McGoon MD and Wason $P$ (2012): Sex differences in the diagnosis, treatment and outcome of patients with pulmonary arterial hypertension enrolled in the registry to evaluate early and long-term pulmonary arterial hypertension disease management. Chest, 141(2):363-73.

22. Song $X$, Zhang $C$, Chen $X$, Chen $Y$ and Shi $Q$ (2015): An excellent result of surgical treatment in patients with severe pulmonary arterial hypertension following mitral valve disease. J Cardiothorac Surg., 10:7045.

23. Thunberg CA, Gaitan BD, Grewal A, Ramakrishna $H$ and Stansbury LG (2013): Pulmonary hypertension in patients undergoing cardiac surgery: pathophysiology, perioperative management and outcomes. J Cardiothorac Vasc Anesth., 27(3):551-72. 


\section{متابعة المرضى ذوي الضفط الشرياني الرئوي شديل الإرتفاع بعد عمليات استبلدال الصمام الميترالي}

خالد محمد محمد علي، محمد شفيق حسن عبدالله، مدحت أحمد رفاعي محمد، هيثم محمد عبدالمعطي حسين

قسم جراحة القلب و الصدر، كلية الطب، جامعة الأزهر

E-mail: sur.khalidsoliman@gmail.com

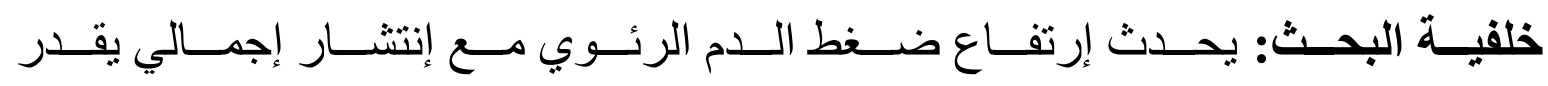

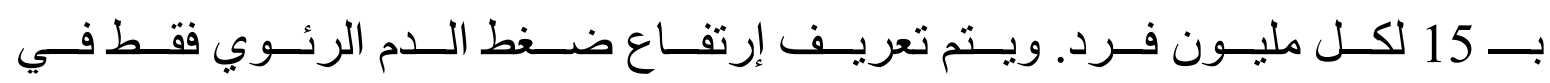

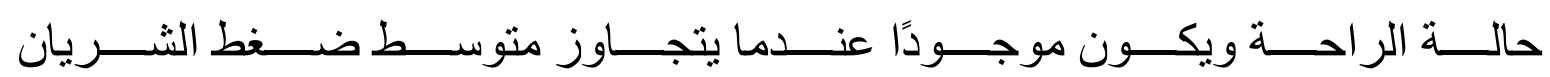
الرئوي عن طريق القسطرة 25 مح زئبق.

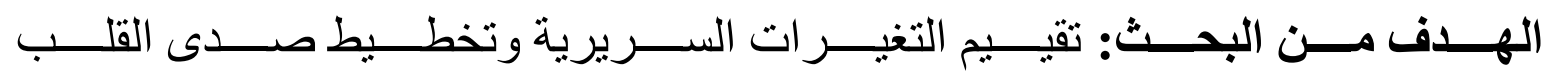

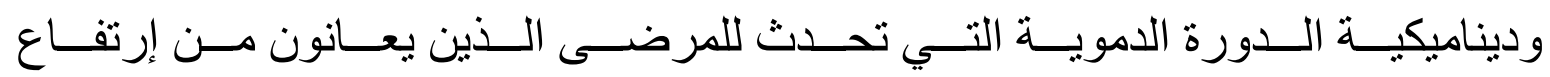

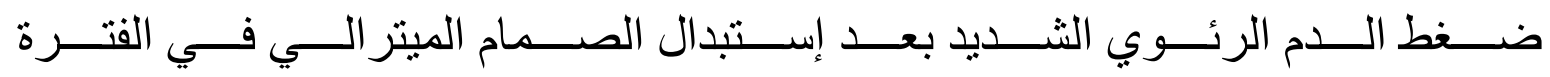
المبكرة و الفترة المتوسطة.

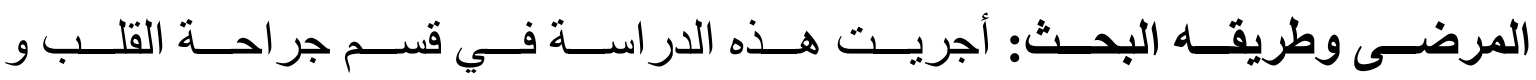

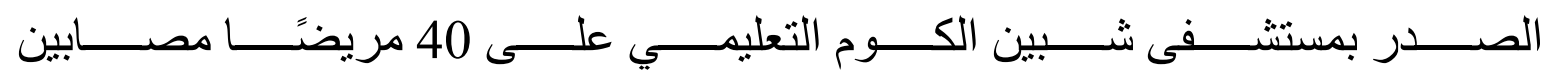

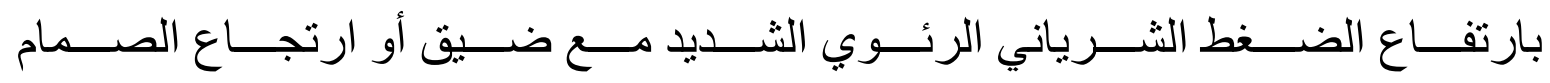

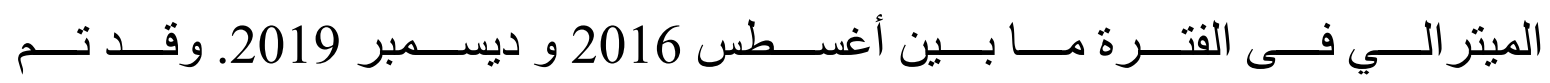

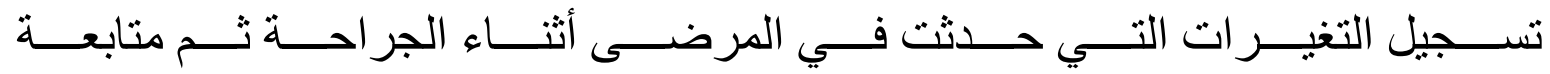

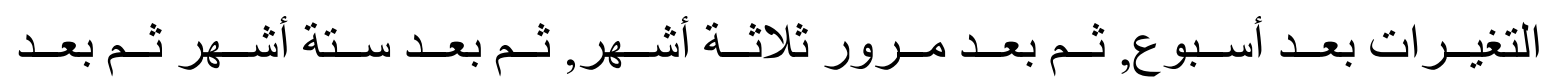
مرور عامين من إجر اء الجراحة.

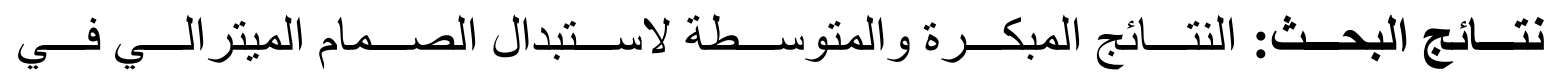

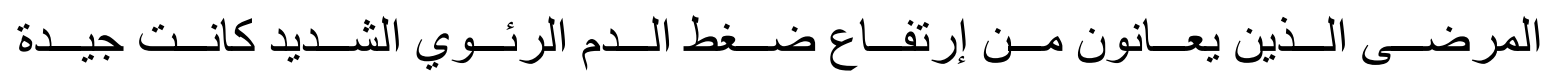




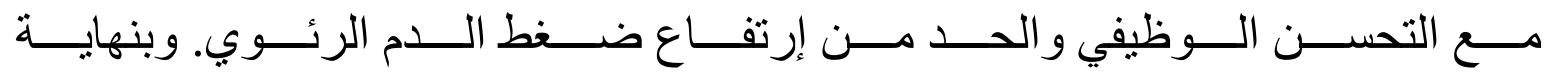

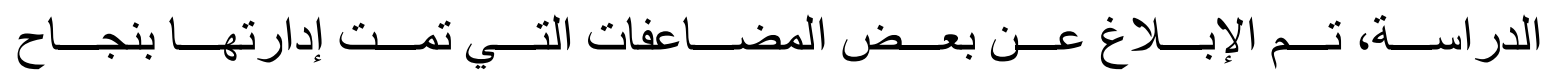
وبلغ معدل البقاء على قيد الحياة لمدة عامين 92.5٪.

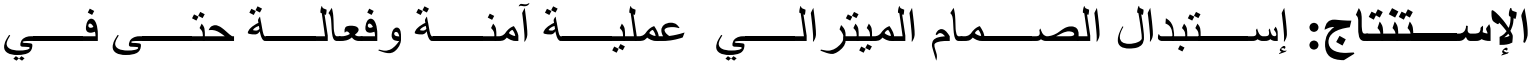

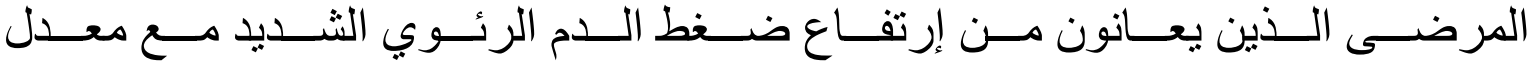

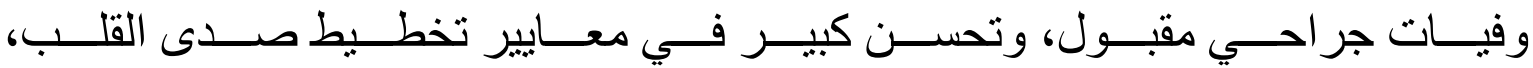
وضغط الدم الرئوي، وتصنيف جمعية نيويورك للقلب.

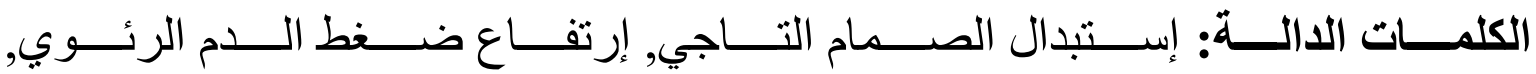
متوسط ضغط الثريان الرئوي. 